\title{
LA CAPACIDAD LEGAL PARA PRESENTAR SOLICITUDES DE MARCAS EN CUBA. ANTINOMIAS ENTRE MATERIAS
}

\author{
DÁNICE VÁZQUEZ D 'ALVARÉ ${ }^{*}$ Y CATERIN MARTÍNEZ DÍAZ
}

\section{RESUMEN}

El trabajo tiene como objetivo analizar la capacidad legal como categoría y las diferentes regulaciones que existen sobre ella en materia civil, mercantil, penal y laboral en Cuba, así como su repercusión en materia de propiedad industrial para la presentación de solicitudes de marcas, a partir de un caso práctico de solicitud de registro de marca ante la Oficina Cubana de la Propiedad Industrial a través de un agente oficial.

Se analiza la disparidad en las edades establecidas para la adquisición de capacidad en las diferentes materias y se hacen propuestas a los examinadores de la Oficina Cubana de la Propiedad Industrial para la aceptación de solicitudes de marcas por menores de 18 años de edad.

Palabras clave: Capacidad legal; capacidad progresiva; propiedad industrial; solicitud de registro de marca; trabajador por cuenta propia.

\footnotetext{
* Doctora en Ciencias Jurídicas, profesora titular de la Facultad de Derecho de la Universidad de La Habana. Árbitro de la Corte Cubana de Arbitraje Comercial Internacional. Agente Oficial de Propiedad Industrial del despacho LEX, S.A. ORCID: 0000000271822672. La Habana (Cuba). Correo-e: danice@lex.uh.cu. Fecha de recepción: 14 de diciembre de 2020. Fecha de aceptación: 26 de enero de 2021. Para citar el artículo: VÁzQuez D`Alvaré, Dánice y Martínez Díaz, Catherin. "La capacidad legal para presentar solicitudes de marcas en Cuba. Antinomias entre materias" en Revista de la propiedad inmaterial n. ${ }^{\circ}$ 31, Universidad Externado de Colombia, enero-julio 2021, pp. 209-233. DOI: https://doi.org/10.18601/16571959.n31.08

** Alumna ayudante del Colectivo de Propiedad Industrial. Cursa quinto año de la carrera de Derecho. La Habana (Cuba). Correo-e: caterinmartinez@lex.uh.cu.
} 
THE LEGAL CAPACITY TO FILE TRADEMARKS APPLICATIONS

IN CUBA. ANTINOMIES BETWEEN SUBJECTS

\section{ABSTRACT}

The objective of this work is to analyze the legal capacity as a category and the different regulations that exist on it in civil, commercial, criminal and labor matters in Cuba and its repercussion on industrial property for the filing of trademark applications, based on a case practical application for trademark registration before the Cuban Industrial Property Office through an Official Agent.

The disparity in the ages established for the acquisition of capacity in the different subjects is analyzed and proposals are made to the examiners of the $\mathrm{Cu}$ ban Office of Industrial Property for the acceptance of trademark applications by minors under 18 years of age.

Keywords: Legal capacity; Progressive capacity; Industrial property; Trademark application; Self-employed.

\section{INTRODUCCIÓN}

La Constitución cubana ${ }^{1}$ establece en el primero de sus artículos, que Cuba es un Estado socialista de derecho y justicia social fundado en el trabajo para el disfrute de la libertad, la equidad, la igualdad, el bienestar y la prosperidad individual y colectiva.

El artículo 21 de la Carta Magna establece que el Estado promueve el avance de la ciencia, la tecnología y la innovación como elementos imprescindibles para el desarrollo económico y social, y en su artículo 62 se les reconocen a las personas los derechos derivados de la creación intelectual.

Por otro lado, el artículo 87 dispone que el Estado y la sociedad reconocen a las personas jóvenes como activos participantes en la sociedad, y que a tales efectos crean las condiciones para el pleno ejercicio de sus derechos.

Siendo la Constitución la ley suprema de nuestro país ${ }^{2}$, queda claro que sus postulados deben informar a todo el sistema económico, político y social cubano, y en su materialización juegan un papel fundamental el resto de las normas jurídicas.

El derecho y la economía van de la mano, y como ha expresado López Medina “... el derecho es una de las principales herramientas de armonización social, es fundamental que los académicos de la economía y del derecho ayuden a construir concepciones y marcos comunes de análisis"3.

1 Constitución de la República de Cuba, Gaceta Oficial Extraordinaria n. ${ }^{\circ} 5$ del 10 de abril del 2019

2 Ibíd., artículo $7.0^{\circ}$.

3 López Medina, Diego E. Las relaciones entre derecho y economía, 4 de junio de 2007. Disponible en [www.dejusticia.org], consultada el 7 de junio de 2020. 
En este juego la propiedad industrial no se queda atrás. Por ello se habla de la economía del conocimiento, término acuñado en 1996 por la Organización para la Cooperación y el Desarrollo Económicos $(\mathrm{OCDE})^{4}$, para dar vida conceptual a un fenómeno de cambio estructural de la economía moderna, en la cual el auge del conocimiento pasaba a ocupar un lugar preponderante 5 .

La economía del conocimiento se acrecienta de una manera exponencial, pues se favorece el intercambio fluido de activos intangibles en pos de incentivar la investigación y el desarrollo de nuevas tecnologías que determinen una mejor calidad de vida y el crecimiento del país. Un recorrido por los anales de la historia de las patentes nos permite reconocer la evolución de una economía centrada básicamente en bienes tangibles como la tierra, las maquinarias o la materia prima, a una economía centrada en el conocimiento, que -sin tornarlas obsoletas- permite un mayor valor agregado ${ }^{6}$.

El problema fundamental de la investigación se centra en la falta de uniformidad en el tratamiento de la mayoría de edad en las diferentes normativas cubanas, en especial en el orden civil, mercantil y laboral, lo que actualmente afecta la solicitud de derechos de marcas de propiedad industrial de los trabajadores por cuenta propia.

Para solucionar dicha problemática nos hemos planteado como objetivo definir pautas a ser utilizadas por los examinadores de marcas de la Oficina Cubana de la Propiedad Industrial (OCPI) en el proceso de concesión de derechos marcarios a trabajadores por cuenta propia entre 16 y 18 años de edad.

Con el fin de lograr tal objetivo, la secuencia metodológica del artículo analiza inicialmente los Lineamientos de la Política Económica y Social del Partido y la Revolución para el período 2016-2021, y la Conceptualización del Modelo Económico y Social Cubano de Desarrollo Socialista ${ }^{7}$ que propicia el trabajo por cuenta propia; posteriormente se analiza la capacidad para el ejercicio del derecho en materia civil mercantil, incluyendo la propiedad industrial, laboral y penal con el fin de revisar las antinomias en relación con la edad establecida para tal ejercicio, refiriéndonos por último a un caso de la práctica en materia de propiedad industrial que evidencia el conflicto que genera la falta de uniformidad en el tratamiento de la mayoría de edad en las diferentes normativas cubanas.

A título de referencia, es necesario señalar que las transformaciones económicas iniciales, como las cooperativas en sectores diferentes al agropecuario, los usufructos onerosos de tierras ${ }^{8}$, el arrendamiento para el sector de los servicios (p. ej., pelu-

4 Organismo internacional que tiene como objetivo promover políticas para mejorar el bienestar social y económico de todos los pueblos del mundo, cooperando para responder a los desafíos económicos, sociales, medioambientales y de buen gobierno. Disponible en [www.economipedia.com], consultada el 3 de diciembre de 2020 .

5 Castelli, Sergio y Larregui, Tobías. Las patentes en la economía del conocimiento. Disponible en [http://comercioyjusticia.info/blog/opinion/las-patentes-en-la-economia-delconocimiento/], consultada el 10 de marzo de 2020.

6 Ídem.

7 Pueden ser consultados en [www.granma.cu].

8 Fue establecido por el Decreto ley 259 de 2008 sobre la entrega de tierras ociosas 
querías y barberías) ${ }^{9}$, la ampliación de las licencias autorizadas para el ejercicio del trabajo por cuenta propia, la posibilidad de que los trabajadores por cuenta propia pudieran establecer relaciones contractuales con empresas estatales ${ }^{10}$, las sociedades mercantiles de capital ciento por ciento cubano y su interacción con la empresa estatal socialista, son notas que aportaron al mercado cubano los antecedentes al modelo económico que hoy se gestiona. Dichas situaciones propiciaron la aparición de nuevos agentes económicos en el territorio cubano, como los trabajadores por cuenta propia y las cooperativas no agropecuarias.

Además de reafirmar la propiedad estatal socialista como forma principal de propiedad en nuestra economía, los Lineamientos de la Política Económica y Social del Partido y la Revolución ${ }^{11}$ para el período 2016-2021 reconocen y promueven otras formas de propiedad como la cooperativa, la mixta, la privada de personas naturales o jurídicas cubanas o totalmente extranjeras, la de organizaciones políticas, la de masas, las sociales y de otras entidades de la sociedad civil, reconociendo que todas funcionan e interactúan en beneficio de la economía ${ }^{12}$, e incluyen la necesidad de fortalecer las políticas de propiedad industrial en Cuba y en los principales mercados externos ${ }^{13}$.

De igual forma, la Conceptualización del Modelo Económico ${ }^{14}$ establece que el reconocimiento y la diversificación de dichas formas de propiedad y de gestión

en usufructo, Gaceta Oficial Extraordinaria n.o 024 del viernes 11 de julio de 2008, año CVI, p. 93, derogado por el vigente Decreto Ley 358 de 2018 y el Decreto 350, Gaceta Oficial Extraordinaria n. ${ }^{\circ} 39$ del 7 de agosto de 2018.

9 Resolución 434/11, Gaceta Oficial Ordinaria n.o 36 del 11 de noviembre de 2011, año cix, p. 1075, que estableció el reglamento para el funcionamiento de las barberías y peluquerías que aplicaban el arrendamiento de inmuebles a trabajadores por cuenta propia, actualmente derogada. La legislación vigente sobre el ejercicio del trabajo por cuenta propia fue publicada en la Gaceta Oficial Ordinaria n. ${ }^{\circ} 85$ del 6 de noviembre de 2019 a saber: Decreto ley n. 383 modificativo del Decreto ley 356 sobre el ejercicio del trabajo por cuenta propia; Decreto ley 384 de la contratación de trabajadores para prestar servicios a las representaciones extranjeras; Decreto ley 385 modificativo de la Ley n. ${ }^{\circ} 113$ del sistema tributario; Decreto ley 386 modificativo del Decreto ley n. ${ }^{\circ} 357$ de las contravenciones personales en el ejercicio del trabajo por cuenta propia, así como las resoluciones del Banco Central de Cuba, del Ministerio del Comercio Interior, del Ministerio de Economía y Planificación y del Ministerio de Finanzas y Precios.

10 Indicaciones a las entidades estatales para la contratación de los productos y servicios de los trabajadores por cuenta propia. Instrucción n.o 7 del 2011 del Ministerio de Economía y Planificación, publicada en $G O E$ n. ${ }^{\circ} 40$ del 21 de noviembre de 2011, actualizada por la Resolución 236 de 2019 del MEP publicada en GOE 85 del 6 de noviembre de 2019.

11 Los Lineamientos fueron aprobados en el marco del vi Congreso del pCC que tuvo lugar en abril de 2011, y posteriormente fueron perfeccionados durante el vir Congreso del pCC y publicados en julio del 2017 junto a la nueva conceptualización y al plan económico-social. Los mismos constituyen una propuesta de actualización del modelo económico cubano, proponiendo conjugar la continuidad y fortaleza del socialismo con el desarrollo económico del país y el aumento de las condiciones de vida de la población.

12 Lineamientos de la Política Económica y Social del Partido y la Revolución, I. Modelo de Gestión Económica. Apartado 3, p. 3.

13 Ibíd., v. Política de Ciencia, Tecnología, Innovación y Medio Ambiente. Apartado 110 , p. 20.

14 La Conceptualización es un documento que expone y fundamenta los objetivos estratégicos del modelo económico, los principios en que se sustenta y las principales transformaciones requeridas, en correspondencia con las condiciones contemporáneas. 
responden al insuficiente desarrollo de las fuerzas productivas, al nivel de socialización alcanzado por la propiedad social, y a los objetivos de la construcción del socialismo al contribuir a movilizar recursos humanos, materiales y financieros, nacionales y extranjeros, reconociendo como objetivos de esas formas de propiedad no estatales posibilitar que el Estado y el Gobierno se concentren en las complejas tareas que les son propias, tributar a la eficiencia integral de la economía, generar empleos productivos, desplegar iniciativas, impulsar las fuerzas productivas, incrementar los ingresos al Presupuesto del Estado y contribuir al bienestar en función de los objetivos del desarrollo socialista ${ }^{15}$.

Tanto los Lineamientos como la Conceptualización tienen su máxima regulación en la Constitución económica ${ }^{16}$, aprobada en 2019, que establece un sistema de economía socialista con dirección planificada ${ }^{17}$, lo que se traduce en la existencia de un mercado bajo regulación estatal, en función de la planificación. Esta formulación recoge la proyección de los Lineamientos referida a la preponderancia de la empresa estatal como sujeto económico, y de la Conceptualización, en relación con el reconocimiento y la diversificación de dichas formas de propiedad y de gestión. El artículo 22 de la Constitución cubana reconoce entre las formas de propiedad: la socialista de todo el pueblo; la cooperativa; la de organizaciones políticas, de masas y sociales; la privada y la mixta; la de instituciones y formas asociativas, y la personal, con un tratamiento paritario en relación con las formas de propiedad sobre los medios fundamentales de producción y la complementariedad entre todos los sujetos económicos que intervienen en la economía cubana.

Esto, a nuestro juicio, no es incompatible con la naturaleza privada de los derechos otorgados por la propiedad industrial, pues en Cuba el reconocimiento de la propiedad privada se extiende a las personas naturales o jurídicas, cubanas o extranjeras, y a nuestro juicio tal como está redactado el artículo 22 supra, los registros en materia de propiedad industrial constituyen propiedad privada y no propiedad personal ${ }^{18}$. Por demás, en nuestra Constitución existe -como al inicio

15 Conceptualización del Modelo Económico y Social Cubano de Desarrollo Socialista, julio de 2017, Capítulo 2: "El Sistema de Formas de Propiedad sobre los Medios de Producción", p. 19.

16 En la doctrina se denomina Constitución económica a las normas que integran un segmento de la codificación constitucional dedicado específicamente a la materia económica-financiera, pudiendo también estas normas encontrarse de forma dispersa en el texto constitucional. Al respecto cfr. a Bidart Campos, Germán J. "La Constitución económica (un esbozo desde el derecho constitucional argentino)", Revista Mexicana de Derecho Constitucional, n. ${ }^{\circ}$ 6, 2002. Este autor define la Constitución económica como el conjunto de normas, principios y valores que, una vez incorporados a la Constitución formal, guardan relación con la economía y son aplicables a la actividad y a las relaciones económico-financieras; cfr. también López Garrido, Diego. "Apuntes para un estudio sobre la Constitución económica”, Revista del Centro de Estudios Constitucionales, n. ${ }^{\circ} 15$, mayo-agosto de 1993, p. 81.

17 “Artículo 18. En la República de Cuba rige un sistema de economía socialista basado en la propiedad de todo el pueblo sobre los medios fundamentales de producción como la forma de propiedad principal, y la dirección planificada de la economía, que tiene en cuenta, regula y controla el mercado en función de los intereses de la sociedad".

18 En la Constitución cubana se define la propiedad personal como aquella que se 
explicamos- un reconocimiento de los derechos intelectuales a favor de personas naturales y jurídicas, quedando en el mismo artículo establecido el límite en el ejercicio de las facultades de estos derechos, en correspondencia con la ley y en función de las políticas públicas, las que implantan las limitaciones en sectores prioritarios como la salud, la agricultura, la industria y el comercio, todo lo cual está relacionado con las características de un sistema socialista como el de Cuba.

Así, el Decreto Ley 203 en materia de marcas permite el registro de marcas a todas las personas naturales y jurídicas, nacionales y extranjeras.

En la economía socialista cubana, como en cualquier economía, es indispensable regular correctamente la propiedad industrial con el fin de fomentar la creatividad y el desarrollo social y económico, donde también participa de manera activa el trabajo por cuenta propia como forma de propiedad privada.

Con el auge del trabajo por cuenta propia ${ }^{19}$, la evolución de su normativa y el incremento considerable de esa forma de gestión ${ }^{20}$, evidenciada en el ascenso del otorgamiento de licencias que obra actualmente ante las direcciones municipales de trabajo (más de $600 \mathrm{mil}^{21}$ trabajadores por cuenta propia inscritos y con licencia otorgada para el ejercicio), se infiere también un aumento del número de personas naturales que solicitan derechos de propiedad industrial, surgiendo situaciones -como las que nos ocupan- que hasta el momento no se habían presentado y requieren de soluciones de la Oficina Cubana de la Propiedad Industrial ${ }^{22}$.

Bajo este contexto de incremento de licencias otorgadas a los trabajadores por cuenta propia (trabajadores por cuenta propia, o trabajadores contratados) y su ejercicio en importantes esferas ${ }^{23}$, es evidente su repercusión en el tráfico económico cubano pues es notable el incremento de bienes y servicios, lo que ha traído como resultado un aumento de la fuerza de trabajo ${ }^{24}$, no solo por el autoempleo

ejerce sobre los bienes que, sin constituir medios de producción, contribuyen a la satisfacción de las necesidades materiales y espirituales de su titular.

19 A nuestro entender este sector pasó a ser una nueva opción de empleo a partir del año 1993, aunque desde mucho antes estaba autorizado el desempeño de ciertas actividades por cuenta propia.

20 En la década de los años 90 comenzó el ejercicio por cuenta propia a pequeña escala, según lo estableció el Decreto ley 14 de 1978 publicado en la Gaceta Oficial Ordinaria del 7 de julio de 1978, p. 261.

$21 \mathrm{La}$ cifra de casi 600 mil, publicada en el sitio [www.cubadebate.cu] el 20 de junio 2019, fue actualizada por la Ministra de Trabajo de Cuba en sesión del Consejo de Ministros, según publicación del 6 de febrero de 2021 [www.granma.cu/cuba-covid-19/2021-02-06/consejo-de-ministros-en-la-senda-de-perfeccionar-el-proyecto-social-yeconómico-cubano-06-02-2021-01-02-53], asegurando que este tipo de empleo representa el $13 \%$ de la ocupación en el país.

22 La Oficina Cubana de la Propiedad Industrial (осpI) es el Órgano de concesión de derechos en Cuba. Está ubicada en la Calle Picota n. ${ }^{\circ} 15$ entre Luz y Acosta, Habana Vieja.

23 Elaboración y venta de alimentos; transporte de carga y pasajeros; arrendamiento de viviendas, habitaciones y espacios; agentes de telecomunicaciones; servicios de belleza; productor o vendedor de artículos varios y trabajadores contratados fundamentalmente para la elaboración y venta de alimentos, y para el transporte de carga y pasajeros. Disponible en [www.cubadebate.cu], consultado el 5 de febrero de 2021.

24 En criterio del viceprimer ministro y titular de Economía y Planificación en Cuba, Alejandro Gil Fernández, además de ampliar las posibilidades de empleo en el trabajo por cuenta propia, se da una respuesta positiva a la implementación del ordenamiento monetario 
sino también debido al número de empleados, con la consiguiente generación de un volumen de ingresos considerable, y la consideración por los especialistas de que un número colosal de estos, que realizan actividad económica, se acercan a la micro empresa ${ }^{25}$ lo que impulsaría la promulgación de una norma para regular las PyMe en Cuba.

Así, el papel ya preponderante de la propiedad industrial se acrecienta y viene a jugar un papel fundamental en la realidad cubana actual, no solo en las relaciones mercantiles de las grandes empresas, sino también en el proceso de desarrollo de los pequeños negocios que ha tenido lugar a partir de la apertura económica y social que ha conllevado la aparición de nuevos agentes económicos en el país.

La existencia de diferentes edades legales establecidas, cuyos detalles abordaremos más adelante, ha creado una antinomia en cuanto a la capacidad de ejercicio de trabajo por cuenta propia y la capacidad para solicitar el registro de una marca que ampare el servicio a prestar como cuentapropista, cuestión que hemos tomado como referencia en nuestro caso de estudio. El hecho de que la legislación vigente en materia laboral tenga como referencia la edad de 17 años $^{26}$ para poder adquirir la condición de trabajador, pero sea la edad de 18 años $^{27}$ la establecida por el Código Civil como la de "mayoría de edad", conlleva la interpretación de que lo establecido en la legislación de propiedad industrial es de 18 años, no pudiendo entonces, un trabajador por cuenta propia, de 17 años con licencia otorgada, presentar la solicitud de registro de marca para distinguir los servicios que prestará o los productos que producirá y/o comercializará como trabajador por cuenta propia.

Se trata de un tema particular y que, a nuestro juicio, requiere de análisis, pues en materia de propiedad industrial no existe antecedente ni publicación que se refiera a la capacidad jurídica de las personas naturales o físicas como solicitantes y titulares de derechos, y que evidentemente no ha sido tenido en cuenta por el legislador cubano, quedando el órgano administrativo decisor en una disyuntiva sobre la aceptación o no de una solicitud de registro de marca por un menor de edad, según la edad establecida en materia civil pero con capacidad para el ejercicio del comercio. Claramente, teniendo en cuenta lo establecido en materia de marcas, el examinador no puede aceptar la solicitud de registro de marca presentada por un menor de 17 años por establecer el artículo 7.1 del Decreto ley 203 "De Marcas y Otros Signos Distintivos" que pueden solicitar aquellos "en pleno ejercicio de la capacidad jurídica”, siendo la edad para el pleno ejercicio de la capacidad jurídica

en el país. Disponible en [www.granma.cu/cuba-covid-19/2021-02-06/consejo-de-ministrosen-la-senda-de-perfeccionar-el-proyecto-social-y-económico-cubano-06-02-2021-01-02-53].

25 Actualmente en la legislación cubana no contamos con los parámetros para considerar cuándo un trabajador por cuenta propia es micro o pequeña empresa. Solamente en la conceptualización del modelo económico cubano aparece una referencia a la cantidad de trabajadores y al volumen de ingreso.

26 Artículo 22 de la Ley 116, Código de Trabajo, cfr. Gaceta Oficial Extraordinaria n. 29 del 17 de junio de 2014.

27 Artículo 29 de la Ley 59 de 1988, Código Civil, Gaceta Oficial Extraordinaria n. ${ }^{\circ}$ 9 del 15 de octubre de 1987. 
la de 18 años, cuestión que es contradictoria con la edad autorizada para trabajar, según la normativa laboral.

\section{ACERCAMIENTO A LA CAPACIDAD LEGAL EN OTRAS MATERIAS}

Aunque la integralidad del derecho -especialmente en un caso- impide la separación de materias, intentaremos, a fines organizativos, realizar un abordaje teórico de algunas materias que vinculan la capacidad legal y nuestra reflexión final sobre el caso de estudio realizado.

\section{AbordaJe CIVIL}

Para referirnos a la capacidad resulta imprescindible remitirnos al Código Civil cubano, el cual establece en su artículo 28.1 que la persona natural tiene capacidad para ser titular de derechos y obligaciones desde su nacimiento. Aquí es necesario abordar entonces la diferencia entre la referida capacidad y la personalidad jurídica a que hace referencia el artículo 24 del mencionado cuerpo normativo.

El término personalidad se refiere al atributo inherente a la condición humana consistente en la aptitud para ser titular de derechos y obligaciones, y, por lo tanto, para ser sujeto de relaciones jurídicas. Si se es persona se tiene personalidad; por tanto, se infiere que el Derecho atribuye personalidad jurídica a todas las personas, como medio para que realicen, durante su existencia, sus fines individuales ${ }^{28}$. Existen varios criterios en relación con el momento del nacimiento de la personalidad jurídica, entre ellos, la teoría de la concepción, la teoría del nacimiento, la teoría de la viabilidad, la teoría ecléctica y la teoría psicológica ${ }^{29}$. Conforme con el Código Civil, el ordenamiento jurídico cubano asume una posición mixta, ya que establece que dicha personalidad comienza con el nacimiento, agregando que el concebido se tiene por nacido para todos los efectos que le sean favorables a condición de que nazca vivo.

Por otro lado se encuentra la capacidad jurídica, desdoblada en dos categorías: la capacidad jurídica de derecho, de goce o de adquisición, y la capacidad jurídica de obrar, de hecho o de acción.

$\mathrm{Al}$ igual que la personalidad, la capacidad jurídica de derecho la tienen todas las personas, pues comienza con su personalidad y acaba con ella, y se muestra como la aptitud para ser, en general e indeterminadamente, titulares de relaciones jurídicas y por tanto de una serie de derechos, deberes, facultades o poderes que forman el contenido de cada relación jurídica concreta. Esta capacidad se man-

28 Sobre el tema de la personalidad jurídica cfr. Ruiz VAras, Irina. Capítulo 2. "La relación jurídica civil”, en Comentarios al Código Civil Cubano, La Habana, Ediciones ONBC, 2012, pp. 22-25.

29 Para profundizar en el estudio de estas teorías cfr. VAldés DíAz, CARIdAd dei Carmen (coord.). Derecho Civil. Parte general, La Habana, Edición Félix Varela, 2000. 
tiene inalterable a lo largo de la vida para todas las personas, y no cabe hablar de limitaciones o restricciones a la misma.

Frente a la capacidad jurídica de derecho se encuentra la capacidad de hecho o de obrar, la cual ya no solo consiste en la aptitud para ser titular de derechos y obligaciones, sino además para ejercerlos por sí mismos de manera efectiva, realizando actos jurídicos que permitan adquirir derechos y asumir obligaciones por las que se responderá directamente. Esta capacidad jurídica sí puede modificarse a lo largo de la vida de cada individuo, ya sea ampliándose o restringiéndose ${ }^{30}$.

Es así que queda claro que el artículo 28.1 del Código Civil hace referencia a la capacidad jurídica de derecho, estando regulado lo relativo a la capacidad de hecho en los artículos 29, 30 y 31 del mencionado cuerpo legal.

Ahora bien, el precitado artículo 29 establece la plena capacidad de obrar, es decir, la total aptitud de una persona para ejercer por sí misma todos los derechos y obligaciones de los que sea sujeto, e interactuar directamente en todas las relaciones jurídicas que le incumben. Según este artículo, para adquirir dicha capacidad plena es determinante el arribo a la mayoría de edad, es decir, los 18 años, o la formalización de matrimonio por parte de menores que ya hayan cumplido los 14 años (para el caso del sexo femenino) y los 16 años (para el caso del sexo masculino). Fuera de este último caso, todo menor de edad carecerá de capacidad de obrar, o la tendrá restringida a determinados y excepcionales actos, en dependencia de lo dispuesto en los artículos 30 y $31^{[31]}$.

En el caso del artículo 30 del Código Civil, a decir de Leonardo Pérez Gallardo ${ }^{32}$, "las necesidades normales de la vida diaria" es un concepto jurídico indeterminado, referido a las necesidades que en el año de promulgación del Código Civil cubano eran imprescindibles, como los alimentos, los estipendios que sirvieran para hacer viajes cortos en el interior del país o las compras de artículos necesarios de pequeño valor. En las condiciones actuales, el estipendio o pensión de los padres puede también destinarse a la compra de artículos necesarios para el adolescente, pero en ningún caso consideramos que el registro de una marca constituya una necesidad normal de un trabajador, amparado en dicha regulación.

No obstante, el Código Civil cubano no reconoce una categoría trascendental que ha venido ocupando un papel fundamental en los debates doctrinales en los últimos años, y que se encuentra refrendada en la Convención de los Derechos del

30 Sobre la capacidad jurídica cfr. Ruiz Varas, Irina. Capítulo 2. "La Relación Jurídica Civil”, cit., pp 25-27.

31 "Artículo 30. Tienen restringida su capacidad para realizar actos jurídicos, salvo para satisfacer sus necesidades normales de la vida diaria: a) los menores de edad que han cumplido 10 años de nacidos, los que pueden disponer del estipendio que les ha sido asignado y, cuando alcancen la edad laboral, de la retribución por su trabajo; b) los que padecen de enfermedad o retraso mental que no los priva totalmente de discernimiento; y c) los que por impedimento físico no pueden expresar su voluntad de modo inequívoco. Artículo 31. Carecen de capacidad para realizar actos jurídicos: a) los menores de 10 años de edad; y b) los mayores de edad que han sido declarados incapaces para regir su persona y bienes".

32 Conferencia de Derecho Civil, Facultad de Derecho, Universidad de La Habana, 2020 , s/p. 
Niño ${ }^{33}$-de la cual Cuba forma parte- ${ }^{34}$, nos referimos a la "capacidad progresiva". Esta figura hace referencia a la evolución gradual de las facultades de los niños y adolescentes en función de su madurez y desenvolvimiento, de manera que puedan ejercer paulatinamente por sí mismos sus derechos conforme al principio de autonomía progresiva ${ }^{35}$. En los últimos tiempos esta tendencia se ha fortalecido, considerándose en muchos casos a la minoría de edad no como una causa de incapacidad de obrar, sino como una limitación a dicha capacidad, limitación que va disminuyendo poco a poco en la medida en que el menor se desarrolla y madura intelectualmente.

Podríamos considerar que es a dicha capacidad progresiva a la que hace referencia el Código Civil cubano cuando regula la capacidad restringida en su artículo 30 , ya que se plantea que los menores de edad que hayan arribado a los diez años no serán totalmente incapaces; no obstante, dicha capacidad restringida se limita a permitir la realización de actos para satisfacer las necesidades normales de la vida diaria, pero la capacidad progresiva va mucho más allá: busca que los menores de edad, sobre todo los adolescentes, puedan llevar a cabo por sí mismos, y atendiendo a su madurez particular, actos jurídicos válidos, sobre todo los que representen un incremento de su patrimonio.

Si bien el Código Civil cubano no reconoce la capacidad progresiva como tal, ello no significa que dicha figura no cuente con reconocimiento en nuestro ordenamiento jurídico, puesto que, como ya mencionamos, desde el año 1991 Cuba ratificó la Convención sobre los Derechos del Niño, y nuestra Constitución establece en su artículo $8 .^{\circ}$ que lo prescrito en los tratados internacionales en vigor para la República de Cuba, se integra al ordenamiento jurídico nacional.

Somos del criterio de que si bien resulta acertada la presunción general que establece el Código Civil cubano de que al arribar a los 18 años se adquiere la plena capacidad, ello no debería significar que no pueda demostrarse, atendiendo a cada caso en particular, que un sujeto que no ha cumplido aún dicha edad sea igualmente capaz para desenvolverse en el ámbito jurídico sin representación o apoyo de terceros, sobre todo si se trata de actos jurídicos que no implican un detrimento de su patrimonio. De hecho, este es precisamente el fundamento que se emplea para otorgarle plena capacidad de obrar a los menores de edad que contraen matrimonio, ya que al realizar ese acto jurídico se presume que dicho menor ha alcanzado la madurez suficiente como para gestionar por sí mismo sus derechos y obligaciones ${ }^{36}$. Entonces, si la formalización del matrimonio destruye

33 Cfr. artículos 5. 12,14 y 28 de la Convención sobre los Derechos del Niño (CDN), adoptada por la Asamblea General de las Naciones Unidas el 20 de noviembre de 1989.

34 La Convención sobre los Derechos del Niño fue firmada por Cuba el 26 de enero de 1990, ratificada el 21 de agosto de 1991 y entró en vigor el 20 de septiembre de ese mismo año.

35 Para profundizar sobre la capacidad progresiva cfr. Valdés Mesa, Caridad. "Capacidad, discapacidad e incapacidad en clave carpenteriana", IUS. Revista del Instituto de Ciencias Jurídicas de Puebla A.C. n. ${ }^{\circ}$ 26, 2010, pp. 39-68.

36 Para abordar el tema del matrimonio formalizado por menores de edad cfr. Mesa 
la presunción de incapacidad de un menor de 18 años de edad, ¿por qué otros actos que demuestren su madurez no pueden igualmente ser tenidos en cuenta para otorgarle la plena capacidad?

Es preciso tener en cuenta estas cuestiones pues no se debe perder de vista que el Código Civil cubano fue promulgado en 1987, es decir, con anterioridad a la ratificación por Cuba de la Convención sobre los Derechos del Niño (1991), y que resulta lógico que a más de treinta años de dicha promulgación sea necesario atemperar algunas cuestiones a la realidad imperante.

Visto, entonces, que en Cuba el menor goza de capacidad jurídica pero no de su ejercicio, a nuestro juicio es un problema la limitación del ejercicio como trabajador por cuenta propia y menor de edad ante la Oficina Cubana de la Propiedad Industrial, pues la restricción de capacidad establecida por el Código Civil -a la que hicimos referencia- no clarifica lo relativo al registro de marcas, quedando el menor, que es además trabajador por cuenta propia, limitado para obtener un registro de marcas u otro signo distintivo cuando no ha arribado a los 18 años. Si bien existe la posibilidad de que el menor actúe por sí, pero asistido por sus padres, sería a nuestro juicio más conveniente que la Oficina Cubana de la Propiedad Industrial aplicara la capacidad progresiva con base en la madurez alcanzada en sus facultades, por no tratarse de un acto dispositivo, considerando además un problema la regulación actual establecida por la Resolución 31 de 2018 del Instituto de Planificación Física, a la que haremos referencia más adelante.

\section{ABORDAJE MERCANTIL Y PROPIEDAD INDUSTRIAL}

En el tema mercantil compartimos el criterio del profesor Bercovitz ${ }^{37}$ cuando señala que, aunque la propiedad industrial surgió de manera autónoma, está integrada al Derecho mercantil, es el motivo por el cual realizamos de conjunto este abordaje.

No obstante, iniciamos el análisis con la definición de empresario con el fin de concluir si existe la posibilidad de que una persona natural tenga esa condición, pues si bien no es privativo de la condición de empresario o comerciante solicitar una marca, pues cualquier persona puede presentar la solicitud, a nuestro juicio el hecho de que se tenga esa condición, o se haga esa función, sugiere, en estos momentos en $\mathrm{Cuba}^{38}$, el hecho de contar con un registro de marcas que distinga los productos o servicios del resto de los competidores.

Castillo, Olga. “Tema ir: El Matrimonio (Segunda Parte)", Derecho de Familia, La Habana, Ediciones Félix Varela, 2001.

37 Bercovitz Rodríguez-Cano, Alberto. Apuntes de Derecho Mercantil, 3. ${ }^{a}$ ed. revisada y puesta al día, Editorial Arazandi, 2002.

38 Aunque en materia de propiedad industrial el Decreto ley 203 no establece la obligatoriedad de registrar marcas y otros signos distintivos y en cambio que en el caso de los nombres comerciales, emblemas empresariales y rótulos de establecimiento se puede adquirir su titularidad por el primer uso, la Resolución 31 del 2018 del Instituto de Planificación Física -norma posterior y de inferior jerarquía- establece la obligatorie- 
Aunque la doctrina ${ }^{39}$ distingue entre empresario mercantil ${ }^{40} \mathrm{y}$ empresario no mercantil ${ }^{41}$, y teniendo en cuenta que en Cuba la legislación que rige la actividad comercial es el Código de Comercio de 1886, definiendo este en sus primeros artículos el régimen general para el comerciante o empresario mercantil individual, como aquellos que, teniendo capacidad legal para ejercer el comercio, se dediquen a él habitualmente, vemos que además de capacidad, se requiere habitualidad.

Estos requisitos quedaron claros en la definición de comerciante ${ }^{42}$ del Código de Comercio, el cual no incorpora el requisito de actuar en nombre propio, que es un requisito importante en la doctrina para distinguir al empresario mercantil del resto de los intervinientes porque se suma al de la habitualidad y la capacidad legal.

Y sobre esto, a nuestro juicio, hay una cuestión que precisar, y es que en Cuba un trabajador por cuenta propia (TPCP) pudiera considerarse como tal y asignársele por tanto la licencia para que opere y aunque su ejercicio se materialice de diferentes formas, una parte de los especialistas cubanos ${ }^{43}$ que han investigado este tema consideran que

... no todos los TPCP en Cuba pueden ser considerados empresarios, solo aquellos que realizan una actividad económica con una estructura sólida que funda trabajo y capital, debido a que hoy, el término TPCP sobrepasa los marcos para lo que fue concebido y vemos en la realidad cubana, algo así como tres modos de actuación del трсг y estos son: trabajador contratado, TPCP que ejerce una actividad económica de muy poca escala y TPCP titular de la licencia que es dueño del negocio y tiene trabajadores que para él laboran. Es a lo que se denominaría trabajador por cuenta ajena.

dad de registrar nombres comerciales como requisito para incluir elementos distintivos o publicitarios en la radicación de carteles, cuestión sobre la que volveremos adelante.

39 Broseta Pont, Manuel y Martínez Sanz, Fernando. Manual de Derecho Mercantil, Editorial Tecnos, 15. ${ }^{a}$ ed., vol. I, 2008, p. 89.

40 Empresario mercantil en sentido estricto, también llamado comerciante. Definido como persona física o jurídica de naturaleza privada que actúa en nombre propio por sí o por medio de otros y realiza para el mercado una actividad comercial, industrial o de servicios. El empresario mercantil por tanto explota en nombre propio una actividad económica comercial, industrial o de servicios.

41 Sujetos que aunque realizan en nombre propio una actividad económica para el mercado, se consideran civiles como, por ejemplo, los denominados por la doctrina "pequeños empresarios" que realizan en nombre propio una actividad económica para el mercado sin disponer de una verdadera empresa, sino con el trabajo propio y el de los miembros de su familia, como podrían ser los agricultores que explotan directa y personalmente sus propias tierras, o los artesanos cuya producción no es totalmente mecanizada o en grandes series, y también los "empresarios civiles por la naturaleza no mercantil de la actividad económica que desarrollan”, que se refiere a empresarios agrícolas individuales y otros cuya actividad no esté descrita en el Código de Comercio.

42 Artículo 1. ${ }^{\circ}$ del Código de Comercio. Recordemos que el término comerciante se utilizó cuando el acto de intercambio era considerado comercio, y el de empresa cuando comenzó la producción en masa o industrial, que generó el término empresario. Esta calificación o no, a los trabajadores por cuenta propia en Cuba, nos obliga a reflexionar sobre los requisitos de capacidad, habitualidad y actuar a nombre propio que lo definen en la doctrina.

43 Mesa Tejeda, Natacha. Sesión científica, Facultad de Derecho, Universidad de La Habana, marzo de 2020, s/p. 
De hecho, al expresar la profesora arriba citada, "sólo aquellos...”, y siguiendo estos "modos de actuación", somos de la creencia que un TPCP lo es si trabaja por sí y para sí y no requiere que nadie trabaje para él, pero también tiene esta licencia el que trabaja como empleado para otro trabajador por cuenta propia, y el que realiza una actividad económica y necesita emplear fuerza de trabajo para ejecutar su proyecto. En todos los casos son titulares de la licencia, pero en el último, a nuestro juicio, puede ser catalogado como empresario y además de la capacidad y la habitualidad, se configura el requisito de actuar en nombre propio que, aunque no aparece en el Código de Comercio, es requisito a apreciar en la práctica. Siguiendo esta línea de pensamiento, se puede ser TPCP y tener terceros como empleados, pero no se puede solicitar el registro de una marca si no se tienen 18 años de edad.

Ahora bien, si estudiamos la teoría del profesor Garrigues ${ }^{44}$, que diferencia entre capacidad para ser comerciante y capacidad para actuar como comerciante, vemos que "para ser comerciante" se requiere la capacidad jurídica general, y según refiere el autor, siguiendo a la legislación española de aquel entonces, podían ser comerciantes los menores de edad e incluso mayores incapacitados, ejerciendo el comercio efectivo en este caso el representante legal; sin embargo, no recaía sobre este último el efecto jurídico de la condición de comerciante excepto el efecto penal. Puede que esta distinción, efectiva para los casos hereditarios, pueda aplicarse en Cuba si tenemos en cuenta que, según esta distinción, excepto en materia penal, el menor de edad tiene capacidad para ser comerciante, no así "para actuar" por sí mismo como comerciante para lo que se requiere mayoría de edad y poseer libre disposición de sus bienes, y en Cuba existe diferencia en las edades establecidas para contar con la capacidad en distintos actos.

Así, toda esta cuestión se hace contradictoria en Cuba, pues una vez que la persona natural cumple los 17 años de edad está apto para trabajar y puede ser portador de una licencia de TPCP que le permite firmar todo tipo de contrato y, por tanto, si solicita un crédito al banco puede contar con el dinero para echar a andar su proyecto.

A nuestro juicio, una vez realizado el somero análisis mercantil que precede, un TPCP en Cuba puede ser calificado -en algunas circunstancias- como empresario con capacidad legal desde los 18 años para realizar una actividad económica determinada para el mercado, momento en el cual tendría la total disposición de sus bienes, aunque en la práctica ello es convalidable desde los 17 años que, con la licencia de TPCP tiene capacidad para contratar y ha mostrado la madurez y responsabilidad requeridas para aplicar la capacidad progresiva.

Si traspolamos estas ideas al ámbito de la propiedad industrial, cuando consultamos lo establecido en los textos legales dedicados a las diversas modalidades ${ }^{45}$

44 Citado por Broseta Pont, Manuel. Op. cit., p. 94.

45 Decreto ley 203, "De marcas y otros signos distintivos"; Decreto ley 290, "De invenciones, modelos de utilidad y diseños industriales"; Decreto ley 291, "De protección 
que componen esta rama, podemos percatarnos de que no existe una regulación uniforme en cuanto a la capacidad jurídica necesaria para la presentación de solicitudes de adquisición de derechos exclusivos.

Es así que el Decreto ley 203, denominado "De Marcas y Otros Signos Distintivos" ${ }^{46}$, dispone en su artículo $7 .^{\circ}$ apartado 1 que pueden solicitar el registro de marcas todas las personas naturales, nacionales y extranjeras, en pleno ejercicio de su capacidad jurídica. Esto nos remite al artículo 29 del Código Civil, y se interpreta entonces como que solo podrán solicitar el registro de una marca los mayores de 18 años de edad, o los que, siendo menores, hayan contraído matrimonio. Lo mismo sucede con lo estipulado en el artículo 7. ${ }^{\circ}$ del Decreto ley 291 de 2011, "De Protección de las Variedades Vegetales" ${ }^{47}$, que establece como requisito para poder solicitar el derecho de obtentor el pleno ejercicio de la capacidad jurídica, así como lo dispuesto en el Decreto ley 292 de 2011, "De los Esquemas de Trazado de Circuitos Integrados" ${ }^{\text {" }}$, donde se requiere el pleno ejercicio de la capacidad jurídica.

Por otro lado, resulta curioso lo establecido en el artículo 90 apartado 1 del Decreto ley 203 sobre las marcas colectivas, donde se dispone que para que una agrupación ${ }^{49}$ pueda registrarlas, los fabricantes, productores, prestadores de servicios o comerciantes que la integran, deben tener capacidad para ser sujetos de derechos y obligaciones. Esto, remitiéndonos a lo explicado anteriormente, no es técnicamente acertado, ya que todas las personas, por el simple hecho de serlo,

de las variedades vegetales"; Decreto ley 292, "De los esquemas de trazado de circuitos integrados".

46 Decreto ley 203 del 24 de diciembre de 1999, “De marcas y otros signos distintivos", Gaceta Oficial Extraordinaria n. 3 del 2 de mayo de 2000, año xcviıı, p. 5.

47 Decreto ley 291 del 20 de noviembre de 2011, "De protección de las variedades vegetales”, Gaceta Oficial Ordinaria n.o 002 del 1. ${ }^{\circ}$ de febrero de 2012, año cx, p. 27.

48 Decreto ley 292 del 20 de noviembre de 2011, "De los esquemas de trazado de circuitos integrados”, Gaceta Oficial Ordinaria n. 002 del 1. ${ }^{\circ}$ de febrero de 2012, año cx, p. 36.

49 Sin ser objeto de esta investigación, consideramos necesario realizar un pequeño análisis sobre lo dispuesto en el artículo 90 del Decreto ley 203 en cuanto a los sujetos que pueden solicitar el registro de una marca colectiva. A nuestro criterio, el legislador no fue lo suficientemente claro en este aspecto, ya que el término "agrupaciones" es demasiado amplio, y si a esto le añadimos la distinción que se establece en el apartado 2 entre agrupaciones (inciso a) y asociaciones, instituciones y otras personas jurídicas (inciso b) la confusión resulta aún mayor, ya que todas las personas jurídicas (con excepción de las fundaciones) son, en primer lugar, una agrupación de personas. Además, consideramos que el término de asociaciones tampoco es acertado, ya que uno de los elementos que caracteriza a las asociaciones es que no tienen ánimo de lucro, y en el apartado 1 se habla de agrupaciones de personas con un interés económico en común. Para profundizar sobre este tema cfr. Valdés Díaz, Caridad del Carmen (coord.). Capítulo Iv: "La persona jurídica", Derecho Civil. Parte General, cit., pp. 155 y ss. Asimismo, tampoco concordamos con la idea de que todas las agrupaciones de personas con un interés económico en común puedan solicitar el registro de una marca colectiva, ya que en esta definición se puede incluir, por ejemplo, a las sociedades mercantiles, las cuales, a pesar de estar compuestas por personas naturales, realizan una actividad propia que es independiente de la actividad individual de sus socios, cuando las marcas colectivas están destinadas a distinguir los productos y servicios que brinden los miembros de determinado ente colectivo. Para profundizar sobre las características de las sociedades mercantiles cfr. Mesa Tejeda, Natacha (coord.), Capítulo iv: "El empresario social”, en Temas de Derecho Mercantil Cubano, La Habana, Edición Félix Varela, 2003, pp. 67 y ss. 
tienen capacidad para ser sujetos de derechos y obligaciones (que es la capacidad jurídica de derecho), lo que no pueden es ostentar la capacidad de ejercer por sí mismos los derechos y obligaciones de los que son titulares.

$\mathrm{Al}$ respecto, el artículo 4. ${ }^{\circ}$ del Decreto ley 290 de 2012, "De las Invenciones y Dibujos y Modelos Industriales" ${ }^{50}$, establece que "Pueden solicitar patentes y registros ante la Oficina, las personas naturales y jurídicas, nacionales y extranjeras, con capacidad legal para ejercer sus derechos y realizar actos jurídicos".

En este caso el legislador se refiere a la obtención de certificados de patentes de invención y certificados de registros de modelos de utilidad ante la ocPI. Aunque en dicho artículo no se establece plena capacidad, se debe permitir el ejercicio de derechos y la realización de actos jurídicos, por lo que, a nuestro juicio, el legislador en este caso fue un poco más flexible.

Lo mismo se pudiera interpretar para los modelos de utilidad, ya que el artículo 76 apartado 1 del Decreto ley 290 nos remite a las disposiciones relativas a la solicitud de la patente para el registro de las denominadas "invenciones menores". De igual forma, asumimos esta idea para los dibujos y modelos industriales, ya que se encuentran regulados en el mismo texto legal con idéntica letra.

Volviendo a los signos distintivos, en el artículo 109 apartado 1 del Decreto ley 203, "De Marcas y otros Signos Distintivos", se establece como requisito para registrar los lemas comerciales una capacidad jurídica "suficiente". La cuestión aquí es determinar qué es lo que define esa suficiencia, pudiendo, a nuestro juicio, aplicar perfectamente el principio de autonomía progresiva plasmado en la Convención sobre los Derechos del Niño, y por tanto considerar que si un menor de edad demuestra que es lo suficientemente maduro y desarrollado podrá solicitar por sí mismo el registro de un lema comercial ante la OCPI.

Teniendo en cuenta que en materia de propiedad industrial la función del registro es otorgar al solicitante derechos exclusivos sobre lo registrado, derechos que se traducen en facultades de naturaleza negativa, como impedir que terceros sin la autorización del titular puedan utilizar el signo, debe entenderse que el hecho de no registrar un signo distintivo no implica que no pueda ser utilizado en el comercio por su poseedor (usuario) -siempre y cuando dicho uso no afecte los derechos de terceros-, especialmente en las modalidades de propiedad industrial, ya que los nombres comerciales, los emblemas empresariales y los rótulos de establecimiento se rigen por el sistema declarativo de adquisición de derechos, por lo que la titularidad, y por tanto los derechos exclusivos, se adquiere con el primer uso en el comercio. Lo anterior está establecido en los artículos 99, 103 apartado 3 y 104 apartado 2 del Decreto ley 203 para nombres comerciales, emblemas empresariales y rótulos de establecimiento, respectivamente.

50 Decreto Ley 290 del 20 de noviembre de 2011, "De las invenciones y modelos y dibujos industriales", Gaceta Oficial Ordinaria del 1.० de febrero de 2012, Gaceta Oficial Extraordinaria n. ${ }^{\circ} 24$ de 16 de abril de 2012, año cx, p. 99. 
Entonces, la pregunta sería: ¿¿tuvo el legislador cubano en cuenta la capacidad legal para el uso de estas modalidades? Y es que en estos preceptos no se establece requisito alguno en cuanto a la capacidad jurídica para poner en uso dichas modalidades en el comercio, por lo que no se establece la necesidad de la plena capacidad jurídica para ser titular de derechos exclusivos sobre ellos debido al uso real y efectivo de los mismos.

Por lo tanto, queda claro que no existe un tratamiento uniforme para todas las modalidades de la propiedad industrial en cuanto a la capacidad jurídica de obrar, lo cual debe corregirse, teniendo en cuenta las ideas relacionadas con la capacidad progresiva.

Mientras tanto, ¿qué hará el examinador cuándo se le presente un caso así? ¿Podrá dar continuidad al procedimiento de registro de marcas presentada por un menor de 18 años?

\section{Abordaje laboral}

Como es prioridad de esta memoria, tendríamos que comenzar por el estudio de la personalidad jurídica laboral como capacidad de ser sujeto de derechos y obligaciones, lo cual parece sencillo en el caso de la persona física con solo ajustarnos a la edad laboral establecida por el Código de Trabajo, pero no lo es pues, como señala Eulalia Viamontes,

La personalidad jurídica laboral del trabajador no surge desde que el individuo se encuentra en el claustro materno como ocurre en la personalidad jurídica civil que protege el patrimonio de la criatura que se encuentra en el vientre de la madre cuando el padre de aquel fallece. La personalidad jurídica laboral nace cuando el individuo adquiere la edad laboral y demuestra tener las condiciones para trabajar... La personalidad jurídica de la entidad laboral nace con la constitución de ésta, ya sea por resolución, por ley o por estatutos ${ }^{51}$.

$\mathrm{Si}$, como se afirmo atrás, la personalidad jurídica laboral surge cuando el individuo adquiere la edad y demuestra tener las condiciones para trabajar, tendríamos que analizar ambos aspectos.

La edad para ser sujeto de una relación jurídico-laboral es 17 años ${ }^{52}$, lo que supone madurez física y psíquica del trabajador, como afirma. Viamontes, cuestión

51 Viamontes Guilbeaux, Eulalia. Derecho laboral cubano. Teoría y legislación, La Habana, Editorial Félix Varela, 2007, p. 93.

52 El artículo 22 de la Ley 116. Código de Trabajo, Gaceta Oficial Extraordinaria n. ${ }^{\circ}$ 29 del 17 de junio de 2014, p. 453 establece: "La capacidad para concertar contratos de trabajo se adquiere a los diecisiete años de edad. Excepcionalmente los empleadores pueden concertar contratos de trabajo con los jóvenes de quince y dieciséis años, con el consentimiento de los padres o tutores, en las circunstancias y condiciones establecidas en este Código y su Reglamento. 
consagrada a escala internacional en los convenios de la Organización Internacional del Trabajo (огт), de muchos de los cuales Cuba forma parte ${ }^{53}$.

Aunque la edad establecida para trabajar es de 17 años, excepcionalmente los adolescentes entre 15 y 16 años pueden iniciar una relación de trabajo si cumplen determinados requisitos ${ }^{54}$, pero, como ya expusimos, la edad no es el único requisito para la capacidad jurídica laboral sino que el trabajador tiene que demostrar tener las condiciones para trabajar, es decir, cumplir los requisitos exigidos para esa ocupación que bien pudiera ser lo que hoy conocemos como "idoneidad" 55 .

Además, como se mencionó inicialmente, a partir de la apertura económica que ha tenido lugar en nuestro país en los últimos años, se ha producido un auge de la participación de los trabajadores por cuenta propia en el tráfico mercantil, lo cual trae como consecuencia que cada vez sea mayor la cantidad de personas naturales que, en su carácter de trabajadores por cuenta propia, solicitan el registro de signos distintivos que identifiquen los productos y servicios que ofrecen. De hecho, la Resolución 31 de 2018 del Instituto de Planificación Física estableció el procedimiento para la autorización que se otorga a los TPCP para la colocación y el contenido de los carteles por las Direcciones Municipales de Planificación Física ${ }^{56}$, con el fin de normar su publicidad, cuestión que no está clara si tenemos en cuenta que los derechos de propiedad industrial nacen de la voluntad de su autor y/o titular, o lo que es lo mismo, la libertad de publicitarse y tener signos distintivos es una premisa de la libertad de empresa.

53 La lista de estos convenios se puede consuñltar en Viamontes Guilbaux. Op. cit., p. 94.

54 Para los detalles, consultar Código de Trabajo, Capítulo v. "Protección especial en el trabajo a los jóvenes de quince a dieciocho años".

55 "Artículo 36. La idoneidad demostrada es el principio para determinar la incorporación al empleo de la persona que se pretende contratar, su permanencia en el cargo, promoción en el trabajo y la capacitación por parte de la entidad; comprende el análisis integral de los requisitos siguientes: a) realización del trabajo con la eficiencia, calidad y productividad requeridas, demostrada en los resultados de su labor; b) cumplimiento de las normas de conducta de carácter general o específicas y las características personales que se exigen en el desempeño de determinados cargos; c) calificación formal exigida, debido a la naturaleza del cargo, mediante la certificación o título emitido por el centro de enseñanza correspondiente. El requisito regulado en el inciso b) se acuerda entre el empleador y la organización sindical, lo que se inscribe en el Convenio Colectivo de Trabajo. En el Reglamento de este Código se regula la autorización excepcional pertinente a lo establecido en el inciso c)".

56 La falta de técnica en la Resolución 31 de 2018 hace que adolezca de definiciones correctas, lo que complejiza su interpretación y aplicación, especialmente al referirse a "signo distintivo de publicidad", "nombre de la actividad que realizan" y "carteles", términos traídos a esta regulación no de la propiedad industrial. Lo claro es la ilegalidad de esta norma, de menor rango y contradictoria con lo establecido en la legislación de marcas y otros signos distintivos, que prima por su carácter especial en la materia; el obstáculo al comercio que supone por la obligatoriedad que impone; la repercusión en el mercado al exigir condiciones a los trabajadores por cuenta propia y no al resto de los agentes económicos, y la exigencia única en relación con los nombres comerciales y no con otras modalidades, en un entendido que no está fundamentado. 
Esta resolución complementa el Decreto ley 356 del 2018 sobre el Ejercicio del Trabajo por Cuenta Propia pero, a nuestro juicio, de forma inadecuada, al establecer en su artículo $4 .^{\circ}$ que:

En los casos en que, para identificar la actividad autorizada, además del nombre de esta se interese utilizar algún signo distintivo de publicidad, el promovente está obligado a registrarlo en la Oficina Cubana de la Propiedad Industrial. Si no se registra, se emite por el Director Municipal de Planificación Física la autorización para colocar el cartel solo con el nombre que se corresponda con la actividad autorizada.

Está claro que una resolución no puede modificar lo establecido en un Decreto ley, en este caso la Resolución 31 de Planificación Física emitida en 2018 que obliga al registro de un signo distintivo, a saber, nombres comerciales, cuando el Decreto ley 203 de 1999 señala que se puede adquirir el derecho sobre estos solo por el uso, no siendo obligatorio el registro, según quedó regulado en el artículo 99.1 de esta normativa, ya que la titularidad del derecho exclusivo sobre un nombre comercial se adquiere por su primer uso en el comercio y termina cuando se abandona el nombre o cesan las actividades de la empresa o institución que lo utiliza. Sin embargo, independientemente de que jerárquicamente tanto el Decreto ley 203 de marcas como el Decreto ley 356 del ejercicio por cuenta propia tienen igual nivel, aplicando los principios del derecho, por su carácter especial en la materia, prima el Decreto ley 203 "De Marcas y Otros Signos Distintivos".

Finalmente, el Decreto ley 356 de 2018 sobre el Ejercicio del Trabajo por Cuenta Propia, estableció en su artículo $2 .^{\circ}$ que pueden ejercer el трср los ciudadanos cubanos y extranjeros residentes permanentes en Cuba mayores de 17 años, y el Decreto ley 383 modificativo del Decreto ley 356 sobre el Ejercicio del Trabajo por Cuenta Propia ${ }^{57}$ mantiene la línea de la edad de autorización para adquirir la condición de trabajador.

\section{Abordaje penal}

El tema de las diferentes edades en la legislación cubana para ser sujeto de derechos y obligaciones también llama la atención en materia penal.

Como lo establece el artículo 16 del actual Código Penal cubano ${ }^{58}$, la responsabilidad penal es exigible a los 16 años de edad cumplidos en el momento de la

57 Cfr. Gaceta Oficial Ordinaria n.o 85 del 6 de noviembre de 2019.

58 "Artículo 16.1. La responsabilidad penal es exigible a las personas naturales y a las personas jurídicas. 2. La responsabilidad penal es exigible a la persona natural a partir de los 16 años de edad cumplidos en el momento de cometer el acto punible. 3. Las personas jurídicas son penalmente responsables por los delitos previstos en este Código o en leyes especiales, cometidos dentro de la propia esfera de acción de dichas personas jurídicas, cuando sean perpetrados por su representación o por acuerdo de sus asociados, sin perjuicio de la responsabilidad penal individual en que hayan incurrido los autores o cómplices en el hecho punible. 4. A los efectos de este Código, le es exigible responsabi- 
comisión del hecho considerado delito, pues se estima que a esa edad el menor ya es capaz de entender las consecuencias de sus actos y de dirigir su conducta.

De acuerdo con el profesor Quirós: “... la responsabilidad jurídico-penal consiste en la obligación que tiene un sujeto imputable de sufrir las consecuencias legalmente instituidas (las sanciones o penas), por la perpetración de un hecho socialmente peligroso y antijurídico también previsto en la ley (los delitos)" ${ }^{259}$.

Una vez en claro que la responsabilidad penal es exigible a las personas naturales a partir de los 16 años de edad, tendríamos entonces que hacer un breve análisis de la exigencia de dicha responsabilidad. Al respecto Quirós explica que únicamente si se trata de un sujeto imputable que comprende la ilicitud de sus actos y es capaz de autodeterminarse se puede aplicar la responsabilidad penal; por tanto, sin imputabilidad no hay responsabilidad.

Así, la capacidad que hasta el momento hemos visto en materia penal adquiere una connotación, podríamos decir, sui géneris, porque alcanza a la madurez, no en su arista explicada cuando en el abordaje civil nos referíamos a la capacidad progresiva, ni tampoco la madurez que asociamos con un ser responsable e idóneo en materia laboral, sino a la madurez vinculada a la salud mental, y que el profesor Quirós adjetiva como madurez de las facultades intelectivas, afectivas y volitivas. Si la salud mental está totalmente abolida, o si el nivel de madurez psíquica resulta insuficiente, se dice que el individuo es inimputable.

La razón de la inimputabilidad por la minoría de edad es idéntica a la inimputabilidad por enfermedad mental, con la única diferencia de que cuando se trata de la minoría de edad no consiste en una perturbación patológica, sino en una realidad biológica ${ }^{60}$.

Una vez establecido, entonces, que la responsabilidad penal es exigible de la persona natural a partir de los 16 años de edad cumplidos en el momento de cometer el acto punible, a nuestro juicio bajo la creencia de que puede discernir entre lo correcto y lo incorrecto, o lo lícito e ilícito, ¿por qué no puede considerarse la misma edad de responsabilidad penal (16 años) para presentar la solicitud de registro de marca?

Somos del criterio de que no tiene sentido que para estos casos (penal, laboral) se valore que un menor de 18 años puede tener la madurez suficiente para asumir ese tipo de relaciones y, además, se llegue al punto de asumir que la tiene, y que para otros casos relacionados con actos que implican un incremento del patrimonio del menor, como son precisamente los actos que atañen al registro de derechos de

lidad penal a las personas jurídicas cuando se trate de las cooperativas, las sociedades y asociaciones constituidas de conformidad con los requisitos establecidos en las leyes, las fundaciones, las empresas no estatales autorizadas para realizar sus actividades, así como las demás entidades no estatales a las que la ley confiere personalidad jurídica.

59 Quirós Pírez, Renén. Manual de Derecho Penal ini, La Habana, Editorial Félix Varela, 2015, p. 3.

60 Ibíd., p. 4 
propiedad industrial, no pueda siquiera plantearse la posibilidad de que ese menor sea capaz de actuar por sí mismo.

Por tanto, reiteramos que al aplicar lo establecido en el artículo $7 .^{\circ}$ apartado 2 del Decreto ley 203, los trabajadores por cuenta propia que tengan 17 años de edad quedan impedidos para solicitar por sí mismos el registro de los signos distintivos que identifiquen los productos y servicios que brindan en su actividad lícita, problemática que debe solucionarse. Y una de las formas de hacerlo sería precisamente tener en cuenta los presupuestos de la capacidad progresiva.

A criterio de Arlín Pérez Duharte ${ }^{61}$, la edad penal de 16 años debe llevar a un análisis en el actual espíritu de perfeccionamiento de las normas penales tanto sustantivas como adjetivas, no solo para garantizar la congruencia con lo dispuesto en la Convención de los Derechos del Niño, sino para determinar un presupuesto etario uniforme que posibilite declarar e informar al individuo cuándo es capaz.

Luego de revisadas estas materias, y vista la responsabilidad desde varios ángulos, somos del criterio de que cuando el examinador de marcas en Cuba se enfrente a esta situación, lejos de esperar a que el solicitante alcance la mayoría de edad, bien puede darle curso a la solicitud amparado en la aplicación de la capacidad progresiva.

\section{ESTUDIO DE CASO EN CUBA}

Como es sabido, en Cuba se trabaja con la figura del Agente Oficial de Propiedad Industrial $^{62}$, adquiriendo esta condición las personas naturales, previo ejercicio de oposición, y cuyo requisito es estar vinculados a los bufetes de abogados autorizados a prestar servicios en materia de propiedad industrial ${ }^{63}$.

En el caso del servicio prestado a personas naturales y jurídicas cubanas y extranjeras se requiere un poder de representación para que el agente oficial pueda actuar ante la Oficina Cubana de la Propiedad Industrial, y en el caso de las personas naturales se requiere además la firma del contrato de prestación de servicios, siendo este último, a nuestro juicio, formal, toda vez que el servicio se presta con pago anticipado, al igual que a las personas naturales y jurídicas extranjeras.

El caso que aquí comentamos es el de una persona natural que en julio de 2019 presentó una solicitud de registro de marcas a través de un agente oficial de propiedad industrial, previa firma de contrato y poder de representación, para una marca mixta en trece clases. El poder lo firmó al contar con 17 años y tres meses

61 Conferencia de Derecho penal. Parte general, Facultad de Derecho, Universidad de La Habana, 2019, s/p.

62 Para más información cfr. VÁzquez D Alvaré, Dánice. "La figura del agente oficial de propiedad industrial. Referencia especial a Cuba” en Vergara Delgado, Teresa (coord.). Enfoques jurídicos diversos en lo privado y familiar en Cuba, Ecuador, Impreso, 2017 , p. 141 .

63 Los bufetes autorizados son: Lex, S.A., Consultoría Jurídica Internacional, Bufete Internacional, Claim S.A., Bufete de Servicios Especializados. 
de edad, o sea, sin haber llegado a los 18 años establecidos por el Código Civil cubano para la mayoría de edad.

Una vez recibida la solicitud en la Oficina Cubana de la Propiedad Industrial, y al momento de realizar el examen formal, el examinador emitió una comunicación oficial al agente oficial solicitándole acreditara "el pleno ejercicio de la capacidad jurídica" del solicitante, lo cual fue contestado, alegando, entre otros, la convalidación de la capacidad por la existencia de una licencia de trabajo por cuenta propia.

Posteriormente, al amparo del artículo 85.5 del Código de Familia, establecido en el artículo 32 del Código Civil cubano, y que de forma supletoria regula la incapacidad de las personas, el examinador emitió un requerimiento oficial solicitando la autorización de los padres del peticionario.

Independientemente de lo que supone la respuesta al requerimiento o acción oficial emitida por la Oficina Cubana de la Propiedad Industrial desde el punto de vista de tiempo y también económico, debemos reflexionar sobre la posibilidad que tiene el examinador de apreciar en casos como este la capacidad progresiva y aceptar la solicitud de registro de marca.

Nótese que quizás han sido cuestionados los principios de trato nacional ${ }^{64}$, de igualdad ${ }^{65}$ o de legalidad ${ }^{66}$, pero el hecho es que quien tiene una licencia para operar como trabajador por cuenta propia está en situación de ventaja en relación con alguien que con la misma edad no posee esa licencia, cuando su intención sea presentar una solicitud de registro de cualquiera de las modalidades previstas en materia de propiedad industrial; en casos como este sugerimos que la Oficina Cubana de la Propiedad Industrial aplique la capacidad progresiva para los solicitantes con 17 años, tanto por vía nacional como internacional, en este caso Madrid (ya sea por Arreglo o Protocolo en tanto Cuba es miembro de ambos), de forma que los nacionales extranjeros no reciban un trato menos favorable que el otorgado a los nacionales.

Si bien la legislación en materia de propiedad industrial no obliga a probar con la solicitud la existencia de intención de uso, del hecho de contar con una

64 Según lo dispuesto en el artículo 2.a apartado 1 del Convenio de París, el principio de trato nacional consiste en que los nacionales de cada uno de los países de la Unión tendrán la misma protección y gozarán de los mismos derechos y ventajas en el resto de los países miembros del Convenio.

65 El principio de igualdad se encuentra plasmado en el artículo 42 de la Constitución cubana, y establece que todas las personas son iguales ante la ley, reciben la misma protección y trato de las autoridades y gozan de los mismos derechos, libertades y oportunidades, sin ninguna discriminación por razones de sexo, género, orientación sexual, identidad de género, edad, origen étnico, color de la piel, creencia religiosa, discapacidad, origen nacional o territorial, o cualquier otra condición o circunstancia personal que implique distinción lesiva a la dignidad humana.

66 Fernández Bulté, Julio. Teoría del Estado y el Derecho, La Habana, Editorial Félix Varela, 2004, señala: "La legalidad es el método de dirección de la sociedad que consiste en la promulgación de leyes que expresan patrones conductuales en los que se contienen los valores emanados de la lucha de clases o impuestos por las clases económicamente dominantes y los cuales, convertidos en ley, deben ser cumplidos estrictamente por el Estado, las organizaciones sociales y políticas y los ciudadanos". 
licencia de тPCP se infiere el uso del signo en el comercio, más aún cuando los vigentes artículos $4 .^{\circ}$ de la Resolución 31 del 2018 de Planificación Física y 13 del Decreto Ley 356 del Ejercicio de Trabajo por Cuenta Propia, obligan al registro de los signos distintivos, contrario a lo establecido por el Decreto Ley 203 "De Marcas y Otros Signos Distintivos" para el uso de los nombres comerciales en la radicación de anuncios y carteles.

Independientemente del tema de la capacidad legal que nos ocupa, vale referirnos a la necesidad de procurar una armonización de la normativa vigente relativa a los TPCP y a la propiedad industrial, cuya solución, a nuestro juicio, no está en la modificación del artículo 7.1 del Decreto Ley 203 en materia de marcas y otros signos distintivos, que establece lo relativo a la capacidad para depositar la solicitud de registro, sino en la aplicación por las autoridades de la capacidad progresiva a los TPCP que aún no hayan cumplido 18 años.

Todo esto se complementa con la correcta interpretación e integración que la Oficina Cubana de la Propiedad Industrial y los Tribunales hagan de las normas jurídicas vinculadas con la esfera de la propiedad industrial.

\section{CONCLUSIONES}

Debe ser derogada la Resolución 31 del 2018 del Instituto de Planificación Física al establecer la obligatoriedad al registro de signos distintivos para los трср y su incompatibilidad con la normativa en materia de propiedad industrial.

Siguiendo a la doctrina mercantil, "para ser comerciante" no se requiere la mayoría de edad, a diferencia de "para actuar como comerciante". Por tal motivo, prima facie no se debe exigir la edad de 18 años cumplidos al momento de presentar la solicitud de registro de marcas, pues para este acto no se requiere poseer libre capacidad de los bienes.

El hecho de que, según la legislación cubana, el menor de edad (menor de 18 años) cuente con una licencia otorgada para el ejercicio por cuenta propia (entregada a partir de los 17 años, mayoría de edad laboral), otorga la capacidad para ser comerciante y solicitar el registro de marca.

En Cuba se debe aplicar la capacidad progresiva a un solicitante de registro de marcas con 17 años de edad y una licencia para operar como cuenta propista, brindando la posibilidad al examinador de marcas de no tener que esperar a los 18 años para atender la solicitud al amparo del Decreto Ley 203 "De Marcas y Otros Signos Distintivos”, teniendo en cuenta, además, que la modificación de la legislación en materia de marcas y otros signos distintivos no está incluida en el programa legislativo del país a corto plazo.

La suficiencia a que se refiere el Decreto ley 203, "De Marcas y Otros Signos Distintivos", para la plena capacidad es, a nuestro juicio, convalidable con la licencia de trabajo por cuenta propia, probada la capacidad progresiva. 
BIBLIOGRAFÍA

\section{FuENTES DOCTRINALES}

Arévalo, E. Jorge y Rajmil, Alicia Beatriz. "Una nueva mirada jurídica sobre la igualdad y la capacidad de las personas", Congreso Internacional sobre Discapacidad y Derecho Humanos, Argentina, 2010.

Bercovitz Rodriguez-Cano, Alberto. Apuntes de Derecho Mercantil, 3. a ed. revisada y puesta al día, Editorial Aranzadi, 2002.

Bidart Campos, Germán J. "La Constitución económica (un esbozo desde el derecho constitucional argentino)", Revista Mexicana de Derecho Constitucional, n. ${ }^{\circ}$ 6, 2002.

Broseta Pont, Manuel y Martínez Sanz, Fernando. Manual de Derecho Mercantil, 15. ${ }^{a}$ ed., vol. I, Editorial Tecnos, 2008.

Castelli, Sergio y Larregui, Tobías. "Las patentes en la economía del conocimiento". Disponible en [http://comercioyjusticia.info/blog/opinion/las-patentes-en-la-economia-del-conocimiento/], consultada el 10 de marzo de 2020.

Fernández Bulté, Julio. Teoría del Estado y el Derecho, La Habana, Editorial Félix Varela. 2004.

Ferriol Molina, Guillermo. Derecho del trabajo. Su actualización, La Habana, Ediciones ONBC, 2018.

García García, Ana Laura. El trabajador por cuenta propia en Cuba: ¿empresario mercantil individual?, Universidad Central Marta Abreu de Las Villas, Facultad de Derecho, junio de 2013.

León Robayo, Édgar Iván. "La posesión de los bienes inmateriales", Revista de Derecho Privado, Universidad de los Andes, Facultad de Derecho, junio de 2006.

López Garrido, Diego. "Apuntes para un estudio sobre la Constitución económica”, Revista del Centro de Estudios Constitucionales, n. ${ }^{\circ}$ 15, mayo-agosto de 1993.

López Medina, Diego E. "Las relaciones entre derecho y economía", 4 de junio de 2007. Disponible en [www.dejusticia.org], consultada el 7 de junio de 2020.

Mesa Castillo, Olga. Derecho de Familia, La Habana, Ediciones Félix Varela, 2001.

Mesa Tejeda, Natacha (coords.). "Capítulo iv: El empresario social", en Temas de Derecho Mercantil Cubano, La Habana, Edición Félix Varela, 2003.

Minyersky, Nelly. "Capacidad progresiva de los niños en el marco de la Convención sobre los derechos del niño", en Hacia una armonización del Derecho de Familia en el Mercosur y países asociados, Argentina, noviembre de 2006. Disponible en [http://www.lexisnexis.com.ar].

Quirós Pírez, Renén. Manual de Derecho Penal III, La Habana, Editorial Félix Varela, 2015.

Ruiz Varas, Irina. Comentarios al Código Civil cubano, La Habana, Ediciones ONBC, 2012. 
Sedletzki, Vanessa y Perrault, Nadine. Las edades minimas legales y la realización de los derechos de los y las adolescentes. Una revisión de la situación en América Latina y el Caribe, UNICEF, enero de 2016.

Valdés Díaz, Caridad del Carmen (coord.). Derecho Civil. Parte general, La Habana, Edición Félix Varela, 2000.

VAldés Mesa, Caridad. "Capacidad, discapacidad e incapacidad en clave carpenteriana”, IUs Revista del Instituto de Ciencias Jurídicas de Puebla A.C., México, n. ${ }^{\circ} 26,2010$.

VÁzquez D`Alvaré, DÁNice. "La figura del agente oficial de propiedad industrial. Referencia especial a Cuba", en Vergara Delgado, Teresa (coord.). Enfoques jurídicos diversos en lo privado y familiar en Cuba, Ecuador, 2017.

Viamontes Guilbeaux, Eulalia. Derecho Laboral cubano. Teoría y legislación, La Habana, Editorial Félix Varela, 2007.

\section{Fuentes LegisLativas}

Constitución de la República de Cuba. Gaceta Oficial Extraordinaria n.o 5 del 10 de abril del 2019.

Convención sobre los Derechos del Niño (CDN). Adoptada por la Asamblea General de las Naciones Unidas el 20 de noviembre de 1989, Gaceta Oficial, 20 de septiembre de 1991.

Código de Comercio de 1886.

Ley 62 del 29 de diciembre de 1987, Código Penal, Gaceta Oficial Edición Especial n. ${ }^{\circ}$ 3, 30 de diciembre de 1987.

Ley 59 de 1988, Código Civil, Gaceta Oficial Extraordinaria n. o 9, 15 de octubre de 1987.

Ley 116 de 2013, Código de Trabajo, Gaceta Oficial Extraordinaria n. ${ }^{\circ} 29,17$ de junio de 2014.

Decreto ley n. ${ }^{\circ} 141$ de 1993 del 8 de septiembre de 1993, sobre el Trabajo por Cuenta Propia, Gaceta Oficial Extraordinaria n. ${ }^{0} 5$.

Decreto ley 203 del 24 de diciembre de 1999, de Marcas y Otros Signos Distintivos, Gaceta Oficial Extraordinaria n. 3 del 2 de mayo de 2000, año XCVIII.

Decreto ley 291 del 20 de noviembre de 2011, de protección de las Variedades Vegetales, Gaceta Oficial Ordinaria n. 2 del 1. ${ }^{\circ}$ de febrero de 2012, año cx.

Decreto ley 292 del 20 de noviembre de 2011, de los esquemas de trazado de circuitos integrados, Gaceta Oficial Ordinaria n. ${ }^{\circ} 2$ del $1 .^{\circ}$ de febrero de 2012, año cX.

Decreto Ley 290 del 20 de noviembre de 2011, de las Invenciones y Modelos y Dibujos Industriales, Gaceta Oficial Ordinaria n. ${ }^{\circ} 2$ del $1 .^{\circ}$ de febrero de 2012, Gaceta Oficial Extraordinaria n. ${ }^{\circ} 24$ del 16 de abril de 2012, año cx.

Decreto ley n. 310 modificativo del Código Penal y de la Ley de Procedimiento Penal, Gaceta Oficial Extraordinaria n. ${ }^{\circ} 18$ del 25 de junio de 2013. 
Decreto ley 356 del 2018, sobre el Ejercicio del Trabajo por Cuenta Propia, Gaceta Oficial Extraordinaria n. ${ }^{\circ} 35$ del 10 de julio de 2018.

Decreto ley 358 de 2018 sobre la Entrega de Tierras Estatales Ociosas en Usufructo, Gaceta Oficial Extraordinaria n. 39 del 7 de agosto de 2018.

Decreto ley 383 modificativo del Decreto ley 356 sobre el Ejercicio del Trabajo por Cuenta Propia. Gaceta Oficial Ordinaria n. ${ }^{\circ} 85$ de 6 de noviembre de 2019.

Decreto 350 de 2018 Reglamento de Decreto ley 300 sobre la Entrega de Tierras Estatales Ociosas en Usufructo, Gaceta Oficial Extraordinaria n. ${ }^{\circ} 39$ del 7 de agosto de 2018.

Resolución Conjunta MTSS y MFP n. ${ }^{\circ} 1$ de 1996 , Reglamento sobre el ejercicio del trabajo por cuenta propia, Gaceta Oficial Ordinaria n. ${ }^{\circ} 16$ de 21 de mayo de 1996, derogada por la Resolución 33 del 2011 del mTss, Gaceta Oficial Extraordinaria n. ${ }^{\circ} 29$ de 2011.

Resolución Conjunta MTsS y MFP n. ${ }^{\circ} 1$ de 1998 , modificativa del Reglamento sobre el ejercicio del trabajo por cuenta propia, Gaceta Oficial Ordinaria n. ${ }^{\circ}$ 22 del 4 de mayo de 1998, derogada,

Resolución 33/2011 del mTss del 6 de septiembre del 2011, Reglamento del ejercicio de trabajo por cuenta propia, Gaceta Oficial Extraordinaria n. ${ }^{\circ} 29$ del 7 de septiembre de 2011, año cix, derogada por el Decreto Ley 383 del 2019, Gaceta Oficial Ordinaria n. ${ }^{\circ} 85$ del 6 de noviembre de 2019.

Resolución 31/2018 del Instituto de Planificación Física, Gaceta Oficial Extraordinaria $n .^{\circ} 35$ del 10 de julio de 2018.

Instrucción n. ${ }^{\circ}$ 7/ 2011 del MEP del 18 de noviembre de 2011, Indicaciones a las entidades estatales para la contratación de los productos y servicios de los trabajadores por cuenta propia, Gaceta Oficial Extraordinaria n. ${ }^{\circ} 40$ del 21 de noviembre de 2011, año CIX, derogada por Resolución 236 de 2019 MEP, Gaceta Oficial Ordinaria n. ${ }^{\circ} 85$ del 6 de noviembre de 2019. 